\title{
PARA QUE AFLORE LO MEJOR DE NOSOTROS: UNA MIRADA A LA ESCUELA DESDE LA PSICOLOGÍA HUMANÍSTICA
}

\author{
TO BRING OUT THE BEST OF US: \\ A LOOK AT THE SCHOOL FROM \\ HUMANISTIC PSYCHOLOGY
}

Manuel Arboccó de los Heros

marboccod@unife.edu.pe

ORCID: https://orcid.org/0000-0002-8481-310X

\section{RESUMEN}

El siguiente ensayo se propone buscar la reflexión sobre algunas dificultades que vienen sucediendo en el ámbito escolar y social, como son: el maltrato a los estudiantes y docentes, el acoso tecnológico entre escolares, la ausencia del trabajo paterno o el descuido emocional de los estudiantes y esto a raíz de datos que hablan de un grupo importante de niños con fobia a la escuela. Además, se enfatiza en el papel de la educación y de los maestros como agentes de cambio para mejorar la situación e intentar recobrar la alegría y la esperanza y, además de ir a aprender al colegio, asistir para vincularnos correctamente y ser felices. El trabajo está dividido en cinco puntos a manera de acápites: a. introducción; b. problemas presentes; c. lo que debemos promover; $d$. para que aflore lo mejor de nosotros; e. conclusión: recobrar la esperanza.

PALABRAS CLAVE

Humanismo pedagógico, el arte en la escuela, telepedagogía, educación emocional, tendencia actualizante.

\section{ABSTRACT}

The following essay proposes to seek reflection on some difficulties that have been happening in the school and social sphere, such as mistreatment of students and teachers, technological harassment between schoolchildren, the absence of parental work or neglect emotional of gifted students, and this from data that speaks of a significant group of children with a school phobia. In addition, it emphasizes the role of education and teachers as agents of change to improve the situation and try to regain joy and hope in addition to going to learn at school, assist to properly link us and be happy. The work is divided into five points as sections: a. introduction; b. present problems; c. what we should promote; $d$. to bring out the best in us; e. conclusion: regaining hope.

\section{KEYWORDS}

Pedagogical humanism, the art in school, telepedagogy, emotional education, trend updating.

\section{A manera de (preocupante) introducción}

0 egún datos publicados hace un par de años, se estima que el $40 \%$ de los niños presenta fobia escolar, esto es animadversión por el colegio (Editora Perú, 2017). Estas cifras son alarmantes y desnudan una compleja situación que abarca desde el descuido parental sumado a la necesidad del sistema de tener muy pronto a los pequeños en centros (quizá no siempre en las mejores condiciones), bajo el cuidado de otras personas y no de sus propios padres, hasta el trabajo poco cuidadoso en los colegios y centros de educación inicial que más que "aulas del saber" son "jaulas de poder" donde imponen a los pequeños determinados contenidos, así como formas de convivencia poco estimulantes y hasta violentas, pasando a veces, por tratos negligentes y poco respetuosos.

Por otro lado, muchos de estos centros y colegios no son más que negocios. Y no tenemos nada contra los negocios, al contrario, bienvenidos sean. Pero es que hay negocios que no pueden realizarse de cualquier manera, por quien sea, como sucede cuando hablamos de la educación y de la formación psíquica, cívica y moral de niños, futuros ciudadanos peruanos.

Mientras vemos países como Finlandia, que ha subido su nivel y posicionamiento en el ranking educativo mundial desde hace varios años, 
por acá generalmente se copian ya superados modelos escolares muy criticados por varios especialistas -como el educador estadounidense Ken Robinson o el recientemente fallecido psiquiatra chileno Claudio Naranjo, por dar dos ejemplos- y documentado por cineastas como Michael Moore en su film La educación en Finlandia o por Jürgen Kláric en su película titulada Un crimen llamado educación.

Sin educación cívica, sin música, sin poesía (porque esos cursos no sirven para buscar trabajo o no demuestran que tan inteligente eres, como diría alguien con una estrecha mirada del colegio), compitiendo todo el tiempo con exámenes permanentes que solo evalúan datos en la memoria, sin verdadero deporte y con horas de horas de tareas mecánicas y poco creativas. $\mathrm{Y}$ entre nosotros, es la realidad nacional, con profesores mal pagados que deben trabajar setenta horas a la semana para sobrevivir $\mathrm{y}$ ninguneados por un sistema que considera más importantes a los "chicos reality" que a los docentes. Salvo excepciones, los colegios son solo un buen negocio para pequeños grupos de empresarios que permiten a los papás tener controlados a sus hijos para ellos poder hacer su vida. Todo aquello alejado de una orientación humanista, cultural y potencializadora de la vida. Así pues, los niños, seguro se percatan de eso y por ahí aparecen esas fobias. ¡Al colegio no! dirán los pequeños y de esa forma se pierde la gran oportunidad de que vivencien desde pequeños lo maravilloso de conocer, de crear, de socializar y de aprender entre todos.

\section{Algunos de los problemas presentes hoy}

\section{- El cyberbullying}

Hoy el llamado cyberbullying (o acoso tecnológico) es un mal en las relaciones interpersonales que ha tomado el tamaño de una pandemia, pues todos convivimos con las redes, la web y demás aparatos tecnológicos y su empleo no está libre del mal uso por parte de jóvenes inmaduros -cuando no con algún desajuste- quienes ven en ellos una forma de acosar, chantajear, burlarse e intimidar.

Se considera al cyberbullying un nuevo tipo de violencia en el contexto escolar, de carácter difamatorio y que opera en las redes sociales. Mensajes de textos intimidatorios, audios que ridiculizan, acusaciones injustas, suplantación de perfiles, propagación de chismes y calumnias, chantaje, divulgación de falsa información, insulto o amenaza, son formas de causar daño de manera inmediata, muchas veces anónima y viral. Lo preocupante es que para algunos estudiantes solo se trata de bromas y juegos, lo cual contribuye a la normalización de la violencia (Dorantes, 2018).

Si bien la tecnología y, en especial las redes, no pueden considerarse malas por esencia, es su uso abusivo o su empleo como vehículo para dañar lo que debe mostrarse y denunciarse para intentar tomar medidas correctivas; es necesario visibilizar los actos violentos para poder superarlos. La acción del que realiza el cyberbullying se caracteriza por la intimidación, hostigamiento, coacción o abuso repetido $\mathrm{y}$ durante un tiempo determinado.

Las redes sociales más utilizadas por los estudiantes (y ya lo vemos desde el nivel primario) son Twitter, Facebook, Youtube e Instagram, además se puede ya afirmar que internet y el ciber espacio afectan el comportamiento, pues deviene en un contexto de construcciones sociales con nuevas características y factores. Es un hecho que el cyberbullying se ha instalado en los ámbitos escolares y universitarios y en las prácticas cotidianas; y los estudiantes que lo ejercen no tienen conciencia plena del alcance de sus actos, ya que impactan de manera negativa a sus compañeros generando diversas consecuencias, entre ellas, el abandono de los estudios, aislamiento, daños psicológicos, cuadros depresivos, ansiedad y hasta tentativas suicidas. Esto abre una nueva necesidad de dialogar y educar en el manejo de esta tecnología. 
Este tema nos permite reflexionar sobre la sociedad y sus nuevas tendencias. Hoy vivimos la era de lo público donde gran parte de las actividades cotidianas que realizamos se comparten en la red, aunque se trate de cosas triviales y sin importancia. El teléfono celular guarda una relación con las necesidades de estatus y de aceptación; sin embargo, los propios estudiantes también manifiestan que este dispositivo puede generar la sensación de esclavitud respecto a su uso (adicción). Debemos decir incluso que ya existe un término -nomofobia - para referirnos al temor irracional (incomodidad y ansiedad) de salir de casa sin el aparato celular.

Las redes sociales son una nueva forma de interacción social y no está exenta de los problemas interpersonales clásicos: malentendidos, calumnias, peleas, chantajes, etc., con la diferencia de que la tecnología permite situaciones como la inmediatez, el alcance de lo expresado, las repercusiones sociales, la viralización. En el acoso escolar se cumplen roles: agresores, víctimas y testigos. Esto tanto en el acoso presencial como en el digital: pero a diferencia del acoso escolar tradicional, el cibernético invade la intimidad del hogar de las personas agredidas a cualquier hora del día o de la noche. Los estudios realizados en varios países demuestran que los jóvenes tienen un escaso conocimiento ético y jurídico sobre las implicancias de la difusión de imágenes y demás contenidos en las redes (Dorantes, 2018). Lo que se vuelve más problemático cuando lo consideran como "normal" y "gracioso" y solo se trata de juegos; es decir, no logran visibilizar el daño que causan en las redes. Es bueno recordar que los acosadores suelen presentar ciertos trastornos de conducta y en casos extremos, conducta disocial. Se produce en ellos una sobrevaloración de la violencia como mecanismo exclusivo para conseguir objetivos, con el distanciamiento de las normas, el abuso de poder $y$ hasta conductas pre-delictivas.

El señalar el acoso como una problemática básicamente estudiantil nos permite ver lo urgente que es incorporar en nuestras aulas la educación psicológica y social. Es urgente que se eduque al ciudadano de estos tiempos (el homo ciber o el homo vídens, como diría Giovanni Sartori) con la ética necesaria que le permita desenvolverse adecuadamente en las redes (Arboccó de los Heros, 2017), y donde palabras como respeto, mesura y reconocimiento se practiquen entre sus miembros. El trabajo tutorial con los niños y jóvenes es una opción para enfrentar este tipo de violencia; junto al trabajo de los padres en casa. Los estudiantes deben tomar conciencia de los peligros que pueden encontrar en las redes sociales. Hay que trabajar con ellos para que se moderen, controlen la información que publican; es decir, se autoregulen y respeten - presencial como virtualmente- a las demás personas. Finalmente, el empleo de toda herramienta tecnológica pasa también por consideraciones éticas.

Humberto Eco dijo alguna vez que las redes sociales le permiten hablar con cierta notoriedad a una gran legión de idiotas. Y no le falta razón. Ahora también, le permite a otra legión molestar, intimidar, calumniar y deshonrar.

\section{- El profesor está arrinconado en algunos colegios}

No solamente algunos colegios son lugares peligrosos para los estudiantes, hoy también lo son para los profesores. Explicaremos seguidamente por qué de tal afirmación.

Estamos hablando hoy de agresiones verbales y hasta físicas a los maestros de escuela; cosa inconcebible en un mundo que defiende el desarrollo de valores y de las llamadas habilidades socioemocionales. ¿Qué podemos esperar de los muchachos cuando ven a sus profesores tratados con tanta violencia $y$ desprecio por parte de sus compañeros y hasta de los mismos padres de familia?

Muchos padres, sinceramente no valoran la educación escolar como es debido y no toman conciencia de la importancia que sus hijos 
cuenten con principios de conducta basados en el respeto a la autoridad, la solidaridad con el prójimo y la empatía con el compañero.

Acusaciones carentes de fundamento, acoso, burlas, desplantes y amenazas son situaciones cotidianas en muchos planteles, donde los directores y profesores se encuentran muchas veces con las manos cruzadas por políticas educativas nacionales que vuelven hoy casi intocable al estudiante y a sus padres. Escuchamos de docentes expresiones como "ya no se les puede decir nada", "ya no pueden repetir el año", "no se les puede suspender por más maldades hechas". Y ojo no hablamos de niños de jardín que merecen toda nuestra consideración y apoyo por su momento evolutivo, sino de muchachas y muchachos mayores, de nivel secundaria, adolescentes próximos a la adultez que ya son bien grandecitos para otras cosas -como dirían algunos-, pero cuando se les debe ayudar a que aprendan de sus errores y faltas, nos encontramos con papás más ciegos que ellos, padres tercos, groseros y con una errada idea de su papel en casos donde la falta de su hijo(a) es grave.

Simplemente no ven los problemas que presentan sus hijos y ya se vienen reportando casos de robos en las aulas, acoso, consumo de alcohol y drogas, violencia física y hasta sexual. Pero los papás no lo ven. También, ciertas asociaciones de padres de familia realmente inútiles y que estorban la correcta conducción de los planteles son otros de los tantos problemas que se presentan en nuestra realidad escolar. Esto hay que decirlo, aunque incomode. Y viene pasando no solo en nuestro país, hay reportes en otros lugares. Es triste y preocupante. ¿De qué sirve que se les dicte clases de trigonometría, de geografía o de inglés avanzado cuando no logran incorporar valores morales y normas de convivencia basadas en la tolerancia, el diálogo, el respeto y el afecto positivo? Vemos alumnos falsamente envalentonados -ante la inoperancia paterna- que desafían, amenazan y ofenden a sus profesores y esto debe parar lo más pronto posible; el ser menor de edad o el ser padre de familia (ahora considerado cliente) no debe ser una excusa para comportarse groseramente $o$ justificar actos negativos.

Con una mezcla de sorpresa y fastidio, cómo se les insulta, discrimina y hasta agrede físicamente a las profesoras y maestros en algunas escuelas públicas y privadas del país ante la ausencia de reacción de las autoridades educativas que no ponen un alto y brindan las sanciones respectivas a estos malos alumnos, así como a sus groseros padres. También es cierto que muchas veces carecen de respuesta no solo por desinterés sino por indefensión administrativa y hasta legal. Y nos preguntamos, ¿Qué podemos esperar de ciertos escolares cuando ven a sus profesores tratados con violencia y desprecio por parte de sus compañeros y hasta de los mismos padres de familia?

Así como se debe investigar y sancionar a las profesoras y maestros cuando cometen una falta, cuando existe un abuso de autoridad, de la misma manera estos hechos que vienen reportándose cada vez con más frecuencia (hasta los hemos visto en vídeos por las redes $y$ en los noticieros), deben terminar con una sanción para esos estudiantes que confunden lo que es la travesura o el reclamo justo con actos de indisciplina y agresiones canallas. No puede ser que un alumno tenga varias notificaciones de su pésimo comportamiento y los padres no tomen cartas en el asunto. Un colegio no puede tener cuasi pandilleros en sus salones, estos casos deben ser atendidos clínicamente a nivel individual y con terapias de familia incluso, siendo los padres responsables de realizarlo. Ser joven no es justificación para ser un antisocial. La familia debe educar y el colegio instruir además de reforzar los valores morales.

De no aprender esta lección -diferenciar lo correcto de lo indebido- es probable que estos escolares sean a futuro esos adultos groseros, intolerantes y egocéntricos que vemos en las calles, bares, tiendas de supermercado y en los hogares, donde existe la violencia, la desidia y la desunión. 
La escuela es como un pequeño experimento donde se prueba -se practica- como seremos luego en la sociedad misma. Para que los escolares valoren el colegio y deseen aprender, sus padres deben hacerlo primero; y de no aprender reglas de conducta, de no aprender a respetar, a autorregularse y a ser tolerantes, el futuro del país es negativo. Por más tecnología y mobiliario que tengan las escuelas, humanamente no avanzaremos. Por más Machu Picchu y variedad gastronómica, como sociedad, no creceremos. Díganselo a los padres, por favor.

\section{- Los niños talentosos no siempre la pasan bien}

No hay suficientes espacios, apoyo económico y logístico para los niños talentosos y los superdotados. Se calcula que podrían existir más de medio millón de estos niños en el país con un coeficiente intelectual de más de 130 puntos, siendo el promedio de 100 puntos.

Especialistas refieren que la superdotación consiste en un conjunto de factores intelectuales que posibilitan "una producción general significativamente distinta de la del grupo normal" (Peña del Agua, 2001, p. 65), mientras que una persona talentosa tiene una capacidad centrada en un aspecto cognitivo o destreza conductual específica.

Ahora, no bastan las pruebas de inteligencia para detectar el talento de una persona. Hay que realizar el estudio de su rendimiento y considerar las opiniones de los que lo conocen, como sus maestras y tutores.

Los test de inteligencia si bien son útiles no pueden medir todas nuestras capacidades o nuestros intereses. Los test de inteligencia, pueden predecir el éxito escolar pero no el éxito profesional o el éxito en la vida, pues para esto se requieren otras condiciones como el juicio social, la empatía, la tolerancia a la frustración, la motivación, el autocontrol, la capacidad de esfuerzo y las habilidades de comunicación y de resolución de problemas.
Además, existen otras variables que influyen en el rendimiento durante las pruebas de inteligencia, como el interés en la evaluación, la salud física, la autoestima y la resistencia. No está demás decir que los psicólogos tenemos algunos problemas metodológicos, por ejemplo, existen pruebas de inteligencia que no están actualizadas para seguir empleándose en el país. Es muy difícil adquirir pruebas originales y se emplean fotocopias que no siempre están bien reproducidas.

Es necesario recordar que el clima familiar es fundamental en el desarrollo intelectual de todo niño, de toda niña. Los aspectos socio-afectivos $\mathrm{y}$ motivacionales deben ser supervisados $\mathrm{y}$ estimulados por los padres y maestras de todos los pequeños. El cerebro "racional" no trabaja bien si la parte afectiva está dañada.

Ser una maestra de un niño muy talentoso requiere una preparación especial. No siempre los docentes estamos capacitados para atender las necesidades y conductas de estos estudiantes. Se puede y se debe estimular las inteligencias y existen algunos programas, aunque no son muchos, para este fin. Hay casos donde a diferencia de lo que se podría pensar -que todo niño superdotado la tiene fácil en la escuelaalgunos sufren de falta de estimulación, abusos y burlas y terminan cansados, aburridos y desestimando la idea de preguntar, de indagar, de destacar. Es un tema interesante y complejo que requiere la atención de especialistas en educación y psicología infantil y escolar.

\section{- ¿Es el lenguaje inclusivo una buena idea en el aula?}

Dejar de decir ellos para decir elles; dejar de escribir nosotros para escribir nosotres; son propuestas que vienen escuchándose cada vez con más fuerza desde hace un par de años, aunque -dicho sea de paso- no han sido aceptados por la Academia de la Lengua Española, decisión que consideramos acertada.

El masculino genérico del término hombres, por poner un ejemplo, no debe invisibilizar a las 
mujeres, pues, se entiende, que se emplea para referirnos a personas de ambos sexos, hombres y mujeres por igual. Véase la siguiente oración: "todos los hombres estamos condenados a ser libres”, decía Sartre. En esta afirmación está claro que hablamos de todos. Pero ¿es necesario modificar una palabra para que todos los grupos sexuales (y los diversos géneros) se sientan invitados y partícipes en el discurso? Asumir hoy que el lenguaje es una herramienta machista es más que exagerado.

La RAE al pronunciarse indica que desde el punto de vista lingüístico "son innecesarios y peligrosos" pues podrían generar más confusión a la hora de comunicar. Citamos: "La mención explícita del femenino solo se justifica cuando la oposición de sexos es relevante en el contexto. La actual tendencia al desdoblamiento indiscriminado del sustantivo en su forma masculina y femenina va contra el principio de economía del lenguaje y se funda en razones extralingüísticas. Por tanto, deben evitarse estas repeticiones, que generan dificultades sintácticas y de concordancia y complican innecesariamente la redacción y la lectura de los textos" (RAE, 2020, disponible en la web). Hay quienes incluso consideran que se debe enseñar en los colegios este "lenguaje inclusivo" desde la infancia.

Ahora bien, a todo esto ¿estamos yendo finalmente al problema de fondo? ¿se logra con estas modificaciones lingüísticas la tan solicitada inclusión? Pues no. Decir jóvenas en vez de jóvenes, todes por todos, nosotres en vez de nosotros, o colocar el símbolo@ o la letra $\mathrm{X}$ para no denotar masculino ni femenino es no solo huachafo, sino innecesario para la causa principal, el respeto y la consideración.

La verdadera $-\mathrm{y}$ a la larga más importanteinclusión se dará cuando, ante la ley, los pedidos de hombres y mujeres sean igualmente escuchados, cuando por un mismo trabajo realizado los sueldos de ambos sean parejos, cuando una mujer que sea asesinada o golpeada por su pareja o ex pareja reciba la justicia del caso por parte del sistema legal, cuando tanto hombres como mujeres (sean heterosexuales, homosexuales, bisexuales o asexuales) sean tratados con respeto, teniendo igual número de deberes y derechos. Finalmente, cuando todos (con distintas preferencias sexuales, con diferencias raciales, étnicas y económicas) vivamos en respeto, equidad y paz. Ese día sí podremos hablar de inclusión efectiva. Lo otro, es solo jugar con el idioma, ya de por sí maltratado desde hace mucho tiempo.

\section{Lo que debemos promover}

\section{- EI arte en la escuela}

Que el arte es necesario, no cabe duda. Que debe promoverse más entre los jóvenes, también. En sus variadas manifestaciones, recordemos: música, danza, pintura, teatro, cine o escultura; el arte ha permitido en quienes lo disfrutan y ejercen hasta una manera de encontrar sentido a la propia existencia. Llena vacíos, confiere significados y afianza el ánimo por encontrar formas de expresarse y de sobrellevar la, a veces, pesada carga de la vida.

El arte es curativo también, permite sublimar nuestros miedos, frustraciones y ansiedades $\mathrm{y}$ facilita la producción creadora, ese impulso por dar vida a una obra que puede generar alguna respuesta también en quien la observa.

Al escribir esto invitamos a los directivos escolares y docentes -como se estila ya en algunos países, Finlandia, por ejemplo- a que incorporen ejercicios artísticos entre sus pupilos, entre sus clases y trabajos. Horas de arte, dentro y fuera de la escuela.

El arte es divertido, puede practicarse también en equipos, aumenta la confianza, brinda un respiro al autoconcepto -siempre vulnerable por tanta competencia académica en la escuela- y es un alivio al estrés escolar, tanto de los docentes como de los estudiantes.

¿Por qué tantas horas de aritmética y tan pocas de cine, pintura o música? ¿por qué tantas horas 
de álgebra y tan pocas de deporte, danza o teatro? Hasta ahora las respuestas no resultan del todo convincentes.

Pruebas internacionales señalan que en matemáticas y en comprensión lectora estamos bastante abajo, quizá eso inclina la balanza a enseñar estas materias más y mejor. Otros piensan que enseñando lo convencional podrán luego dar los exámenes de admisión a las universidades; pero olvidan ellos que el propósito del colegio no es prepararnos para un examen. Demos también un espacio a otras áreas donde los estudiantes no solo podrán aprender algunos contenidos sino tener experiencias que los motiven $\mathrm{y}$, de pronto, ayuden a autoconocerse un poco más y a sacar sus intereses y potencialidades. No todos egresarán del colegio e irán a estudiar ingeniería, derecho o medicina. Hay quienes se inclinarán por la música, el diseño, la literatura o la fotografía; y estas disciplinares son tan válidas, dignas e importantes como las carreras clásicas mencionadas.

El arte no puede hacernos daño, al contrario, una persona sensibilizada en la pintura, la poesía o el teatro, podrá diferenciar lo estético de lo grosero, la calidad de lo barato y estará en posibilidad de ser un ciudadano más exigente y más cauto. Alguien formado en la historia del arte podrá conocer de personajes y de sus obras que trascendieron épocas. Un muchacho que vea buen cine y variado, entenderá mejor la vida con sus alegrías, dramas y esperanzas. El que haya oído música no se dejará timar por los hits del momento.

Sin ser utópicos, pensamos que brindar horas de deporte, teatro, música, pintura, escultura y cine en la escuela, junto con los cursos clásicos, puede fomentar en el estudiantado un espíritu crítico, una actitud más contemplativa, un sentido ético e inclusivo que de pronto aún les está costando conseguir y es que las ciencias puras y exactas todavía no pueden decirnos lo que es bello, justo y humano. Y el arte sí que puede, o al menos lo intenta.

\section{- Gardner y las distintas inteligencias humanas}

Desde que el psicólogo de Harvard, Howard Gardner, publicara sus trabajos señalando la existencia de múltiples inteligencias humanas, la educación no volvería a ser la misma. Desde hace más de treinta años -en que publicó sus trabajos- no solo los psicólogos cognitivos sino los docentes conocen que los talentos son distintos y variados y eso ha influido a la hora de hablar del aprendizaje y del rendimiento académico.

El mérito de Gardner fue promover y validar la diversidad mental en la forma de resolver problemas (clásica manera de reconocer a la inteligencia) y cuestionando clasificaciones que consideraban solo dos o hasta tres tipos de inteligencias (y todas muy ligadas al rendimiento escolar, como la comprensión verbal y la lógica), dejando de lado otros aspectos como la ejecución musical, la habilidad social y el autodominio.

Asimismo, nos cuenta en una entrevista realizada al divulgador español Eduard Punset (fallecido en el 2019) que su aventura inició cuando en vez de usar el término talento o habilidad empleó el término inteligencia, concepto que estaba digámoslo así- en manos de los psicometristas y de los creadores de pruebas intelectuales. La inteligencia, critica él, no se reduce al número (coeficiente) que se obtiene tras ser evaluado con una de las pruebas estandarizadas; es más, el coeficiente intelectual (C.I.) suele ser una medida sesgada de la producción y capacidad de una persona al no considerar más que preguntas generalmente relacionadas a lo aprendido en la escuela, descartando otras condiciones mentales y sociales necesarias para el éxito no solo académico y profesional, sino general.

La propuesta se resume en la existencia de ocho tipos de inteligencias diversas, a saber: la lógico matemática (propia de un físico), la verballingüística (presente en un escritor), la visoespacial (como la que presenta un arquitecto), la corporal cinestésica (pensamos en Pelé), la 
musical (un Mozart sería un buen ejemplo), la intrapersonal (que involucra autoconocimiento y autodominio), la interpersonal o social (presente en un líder como Gandhi) y la naturalista (pensamos en los biólogos y agricultores). Inicialmente formuló siete dominios, luego adicionaría ésta última, la naturalista, pensando en gente como Charles Darwin.

Cierto es que ha tenido sus críticos, pues le achacan que su propuesta es "tan general" que todos o casi todos en el mundo serían seres inteligentes. Ciertamente lo que critica Gardner es que la escuela promedio no permite identificar ni desarrollar las inteligencias humanas pues su mirada está casi siempre reducida a ser bueno en los cursos de matemáticas o de lenguaje, ignorando la destreza en pintura, en música, en el liderazgo y en el conocimiento de la naturaleza. Él mismo reconoce hoy ser más un asesor en temas psicoeducativos que un psicólogo cognitivo.

Gardner viene evaluando, estudiando y trabajando en la que podría ser la novena, la llamada inteligencia existencial. Quizá pronto haya más novedades.

\section{- Importancia del deporte y de la educación física}

Aún se observa, lamentablemente, quienes consideran que la hora de Educación Física no es importante dentro de las asignaturas escolares $\mathrm{y}$, peor aún, dentro de la educación integral de todo ser humano.

Se considera erróneamente también que esa hora debe ser un tiempo muerto donde los muchachos y las jovencitas solo deben ponerse ropa deportiva y correr un rato por el patio, junto a uno que otro amago de ejercicio físico. Craso error. Según la Organización Mundial de la Salud las personas entre los 5 y los 17 años deberían realizar como mínimo entre 30 y 60 minutos diarios de ejercicio físico, ya que esto, como veremos, permite una serie de beneficios.
Comencemos, primero en lo corporal, la práctica sistemática del deporte individual o colectivo previene la obesidad, las enfermedades cardiovasculares y pulmonares, mejora la psicomotricidad, reduce el estrés, ayuda al desarrollo de su aparato locomotor y al fortalecimiento de sus músculos; en lo social y lo psíquico, favorece la autodisciplina, puede facilitar el trabajo en equipo y aumentar la tolerancia a la frustración, invita a redireccionar los impulsos y la rabia y ayuda a superar la timidez, así como produce endorfinas producto de la alegría y el placer concomitante a las actividades.

Según datos oficiales solo una quinta parte de las escuelas públicas brinda varias horas semanales de educación física a cargo de los profesionales del área (no improvisados o cualquier profesor que ayude de buena gente) y con la logística del caso, es decir con los ambientes y la infraestructura conveniente para la buena práctica del deporte. Si a eso le sumáramos una buena alimentación, una buena educación cognitiva y moral, estaríamos hablando de una escolaridad que cumpla con el papel principal de toda institución educativa: la formación de seres humanos sanos, sensibles, inteligentes y cívicos.

Ya es momento de ver a los muchachos practicar deporte y no solo fútbol, sino todas las otras variedades existentes: basketball, voleibol, natación, atletismo, tenis, etc. ¿Pecamos de soñadores? Quizá, pero es mejor soñar con algo que pueda aparecer -si nos decidimos a implementarlo con políticas generosas, honestas y bien planificadas-que solo ver la triste y a veces deplorable realidad de muchas instituciones precarias y algunas cayéndose a pedazos. ¿Así queremos más campeones y campeonas?, ¿así queremos más y mejores ciudadanos?

\section{- Buen día, por favor, gracias}

Buen día, por favor y gracias. Tres palabras ciertamente imprescindibles en estos tiempos de rapidez, vida automática y ensimismamiento 
casi patológico. Tres palabras necesarias en las relaciones humanas que tienen un efecto positivo y hasta lubricante en los contactos personales. Decimos lubricante pues ayudan a disminuir la fricción y pueden preparar el camino para una interacción más respetuosa y hasta amistosa.

El "buen día" (o buenos días como se suele escuchar más frecuentemente) abre la mañana deseándole al prójimo un inicio positivo en su trabajo, escuela, negocio o tarea cualquiera. El "por favor" nos recuerda que nadie está a "nuestro servicio exclusivo" sino que, si bien él o ella puede estar trabajando en atención al público, lo reconozco como otro digno y válido y abro una solicitud o pedido de manera cortés y respetuosa. Finalmente, las "gracias" es el gesto de gratitud ante el apoyo recibido, el producto ofrecido o el servicio brindado. Cierra así una transacción amable y educada.

Vemos personas que olvidan estas tres palabras en su trato social. Y lo olvidan reiteradamente; no pudiendo disculparse ya por estar desatentos o pensando en las propias musarañas. Y no solo lo olvidan las personas sin mayor educación; muchas veces son los estudiantes universitarios y los profesionales, los que desatienden esto, lo cual ya cobra un tinte de mayor preocupación. ¿De qué nos sirve tener estudios superiores si no hemos aprendido las reglas mínimas de convivencia?

En estos tiempos de aplicativos, de delivery y autoservicio, la interacción humana es cada vez más corta, impersonal y fría, hasta casi burocrática. Sumergidos tal como andamos en nuestros modernos celulares y equipos de música, nos olvidamos ya de los demás y las mínimas reglas de cortesía se ven agonizantes. Cada quien está en lo suyo y el otro es menos que un fantasma o un peldaño para alcanzar lo que quiero.
No es necesario ser doctor o magíster en alguna carrera para ser cortés. Y si alguien piensa que por tener estudios o dinero o cierto estatus está libre de tener que saludar o agradecer a quien le sirve o le brinda apoyo, pues está equivocado. Por eso consideramos que estos modales deben ser inculcados desde muy temprano en casa y fortalecidos en la escuela; porque si no se aprenden oportunamente de pequeños, luego ya será tarde. Tan importante como saber escribir, tener agilidad para el cálculo mental o manejar bien un idioma, también debemos practicar estos elementos esenciales de la convivencia social. $\mathrm{Y}$ los maestros y adultos en general, debemos enseñárselo a los más pequeños.

\section{- La telepedagogía}

Sabemos que existe esa llamada "televisión basura" que no es más que un conjunto de programas de televisión cuyos contenidos son muy pobres tanto en la propuesta cognitiva como en la socio-afectiva que nos brindan, por decir dos aspectos centrales que forman la riqueza psicológica de cualquier ser humano. "Este tipo de televisión de contenidos superficiales, manipuladores, embrutecedores, chabacanos $\mathrm{y}$ violentos es a lo que nos referiremos con TV basura. Muchos temas son tratados con la superficialidad propia de quien únicamente busca el espectáculo lucrativo, generando actitudes y representaciones negativas en aquel sector de la audiencia que tiene en la televisión a su única -y más creíble- fuente de información y-quizá- de educación" 1

Los canales de TV son responsables (lo suelen olvidar) de los contenidos que emiten, así como los padres de orientar y acompañar a sus hijos cuando ven televisión. Los colegios, por su parte, deben aprovechar las horas para debatir, discutir y orientar a los niños y adolescentes respecto a lo que miran en la televisión. Y el

1. Para un trabajo más extenso sobre el tema, ver: Arboccó de los Heros, M. y O’Brien, J. (2012). Impacto de la televisión basura en la mente y la conducta de niños y adolescentes. Avances en Psicología, 2, pp. 43-57. UNIFÉ, Lima. Recuperado de: http://www.unife.edu. pe/publicaciones/revistas/psicologia/2012/2/ Avances.Arbocco.5.pdf 
gobierno es responsable de fomentar programas especialmente dedicados a mejorar el nivel educativo y cultural (Ponce Alberti, 2001). Eso está claro. Puede alegarse que la TV no está obligada a educar, lo cual es cierto. Para eso están los padres y luego el colegio, pero las empresas televisivas deben asumir su responsabilidad social y desarrollar algo de consciencia social, aunque es poco lo que se pueda exigir a quienes no son ni pedagogos ni filósofos ni científicos sociales sino más bien empresarios, de esos que solo ven en el "business" y la ganancia millonaria el objetivo primordial de una empresa. Se muestre lo que se muestre. El lingüista y filósofo Noam Chomsky nos recuerda que una forma de manipular al espectador y consumidor moderno es "estimular al público a ser complaciente con la mediocridad. Promover al público a creer que es moda el hecho de ser estúpido, vulgar e inculto" (Chomsky, 2012, disponible en la web). No dejemos que los niños crean eso.

Según Ponce Alberti (2001) en su trabajo sobre la televisión peruana, nos dice: "La televisión no educa, no presenta opciones suficientes de programas positivos, no vertebra el espacio público de comunicación actual que se basa en la imagen. Su carácter comercial la lleva a contenidos de baja calidad y a resaltar lo negativo, afectando los valores" (p. 125).

Ahora, ante el penoso estado de nuestra televisión nacional y sin satanizarla, pero buscando alguna forma de protegernos de sus vulgares y tontos espacios es que proponemos algunas sugerencias a tener en cuenta. Algunas demandarán tiempo y solo se conseguirán trabajando cuando no luchando por alcanzarlas; otras son sencillas, cotidianas y fáciles de practicar:

- Mejorar la selección de la programación que vemos en casa. Cuantas más personas vean un programa basura más posibilidades tendrá de perdurar. Seleccionar los programas educativos, informativos y de entretenimiento es una tarea a cargo de los adultos y tutores quienes harán una suerte de lo que nosotros llamamos "telepedagogía".
- Rechazar la programación y propaganda violenta, discriminatoria, dogmática, incoherente y supersticiosa.

- Educar a los niños y jóvenes en un espíritu crítico ante los contenidos mostrados en los medios. No se trata de tragar TV, sino de alimentarse con ella, de ser posible.

- Debemos requerir y exigir de los medios un comportamiento ético (código moral en radio, prensa y TV). Tarea difícil pues es pelear contra millones de dólares en juego, pero desde donde nos toque debemos tener una posición crítica ante lo que no contribuya a vivir en un país mejor.

- Es urgente una mayor participación de los profesionales de las ciencias sociales, analizando y denunciando a las empresas que embrutecen, dañan, restringen el desarrollo humano en todo su potencial.

- Promover la exposición a la TV como una opción y no como un hábito. Como decía el pensador uruguayo Eduardo Galeano "ojalá llegue el día donde el televisor deje de ser tratado como el miembro más importante de la familia y sea tratado como la plancha o el lavarropas." (Galeano, 2011, en vídeo). Proponemos realizar otras actividades en vez de sólo distraerse viendo TV; por ejemplo: leer, practicar algún deporte, pasear, asistir al teatro, pintar, ir al cine, tocar algún instrumento musical, estudiar cursos. Recordamos haber escuchado a nuestro Premio Nobel Mario Vargas Llosa denominar a la literatura "un entretenimiento, pero superior". En un hogar donde sus miembros miran televisión durante veinte o treinta horas semanales, ya no queda tiempo para otros pasatiempos o actividades. Además, la TV basura empobrece el aparato cognitivo.

- Discutir con los niños, adolescentes y jóvenes los programas, las canciones que pasan por las radios y las películas que el sistema nos suele ofrecer y orientarlos cada vez que se pueda. 
- Esta recomendación va para los adultos de casa y en especial para los padres: reducir la cantidad de aparatos de televisión. Recordamos, ya hace años de esto, como al contar con un televisor en casa esto llevaba a la mirada colectiva (familiar) de una serie o programa, la cual iba luego acompañada por alguna conversación sobre lo visto. Hoy es fácil encontrar tres, cuatro o cinco aparatos de televisión repartidos en las casas (algunos lo llaman prosperidad), facilitando esto una suerte de separación familiar donde cada uno observa el mismo programa, muchas veces a solas, cual autista encerrado en sus propias contemplaciones. A más televisores puede que estén más separados los miembros de una familia. Lo planteamos para el debate.

- Y no nos dejemos llevar por el supuesto "éxito" de ciertos programas o espacios que son anunciados con bombos y platillos como las revelaciones televisivas de la época o las que han revolucionado lo hecho en la pantalla. Conviene recordar que más no siempre es mejor. Además, existe toda una parafernalia empresarial para posicionarlas. Basta recordar los avances en noticieros y los titulares de ciertos diarios de la capital que nos "noticiaban" de lo "último" y "lo mejor" de la serie, programa cuya misma empresa produce, y que horas después será proyectada en el canal de su empresa. Así se asumen como "juez y parte" y tienen todo un montaje de sugestión y convencimiento popular. No seamos débiles mentales, ejerzamos nuestro juicio crítico y recordemos que no todo es la TV. Busquemos otros pasatiempos superiores.

\section{- La personalidad de la maestra y las libretas de notas}

Llegados esos tiempos, cuando ya se han recogido las libretas de notas escolares o tenemos ya los promedios finales de los cursos llevados en el colegio y en la universidad, es bueno para todos los involucrados recordar que el rendimiento académico es resultado de, consideramos, tres condiciones básicas:

La primera de esas condiciones, es el compromiso asumido (compromiso con tu institución, con tu carrera, con la asignatura, con tu papel de estudiante, con tu rol de académico). La segunda condición es el esfuerzo realizado (prioridades asumidas, horas de sueño invertidas en estudiar e investigar, tiempo dedicado a la lectura, algunas amanecidas preparando exposiciones, exámenes y monografías). Y la tercera condición es el talento personal (eso no te lo da ninguna universidad ni ningún colegio, tú lo tienes o no; por ejemplo: un buen coeficiente intelectual, buena memoria, capacidad de análisis, pasión por el estudio, alto razonamiento lógico, comprensión verbal, habilidades diversas, entre otros aspectos).

Debemos aceptar que, si nos falta una de estas condiciones, no podemos esperar un alto rendimiento académico y unas muy altas calificaciones. Ahora, si nos faltan dos, es mejor que reflexionemos qué estamos haciendo en la Universidad (o cómo estamos asumiendo nuestro papel de escolares, en los casos de los más chicos que aún no pisan una universidad). Ya no decimos nada si nos faltan las tres condiciones arriba señaladas. Aunque a veces a muchos estudiantes les faltan las tres.

Hay, sin embargo, una cuarta y muy importante: El docente que nos tocó. El papel de la profesora o del profesor es fundamental como bien lo estudió, entre otros especialistas, Robert Rosenthal, famoso psicólogo de la Universidad de California (pueden buscar el llamado Efecto Pigmalión en el aula, propuesta estudiada por él). El clima en el aula, la pasión del docente, sus conocimientos, su dedicación y esfuerzo para que sus dirigidos aprendan, su capacidad de volver significativa una materia o un tema que de pronto inicialmente no lo es así para el estudiante, su estado de ánimo, su trato y su calidad humana influyen notablemente en el rendimiento estudiantil. 
Esa condición número cuatro, la personalidad del profesor o profesora, puede inclusive marcar la diferencia entre el estudiante que abandona los estudios y se convence de "lo tonto que es" y el estudiante que se inspira y decide seguir una carrera. A los que nos dedicamos a la docencia realmente nos consta.

\section{- Capacitar a los capacitadores}

Hace unos pocos años, a raíz de hechos penosos en las relaciones entre hombres y mujeres, se fue haciendo más visible la importancia de incluir en los colegios -con más énfasis que antes- los temas de la igualdad, la no discriminación, la tolerancia y la inclusión. Y todo apuntaba a la educación escolar, pues, es desde temprano donde ciertas actitudes y valores deben incorporarse con la esperanza de luego despertar con una juventud formada en principios de equidad, respeto y paz.

Noticias de abusos de todo tipo a personas en las calles, estadísticas de feminicidios incrementándose, desigualdades económicas laborales, entre otros hechos, llevaron a la aparición de colectivos sociales que reclamaban respeto y tolerancia; en una palabra: amor. Amor al prójimo. No faltaría, lamentablemente, la aparición de algunos colectivos desvirtuados, fundamentalistas, radicales e igual de violentos en su discurso y acción que francamente generaban menos apoyo a la causa original.

Y así se llegó al tema de la educación de los niños, y a las políticas educativas para promover una cultura equitativa y pacífica. Sin embargo, alzaron muchos la voz al temer que se tomen decisiones apresuradas y se estimulen contenidos inadecuados en los salones. Aparecieron en los carteles y en los discursos términos como ideologías, género, masturbación, sexismo, exposición indebida, genitales y otros tantos; y recién algunos distraídos papás se pusieron a pensar efectivamente qué les enseñan en los colegios a nuestros hijos. Recién vimos una preocupación. Pero nosotros nos hacemos una pregunta que hasta ahora no escuchamos se haya hecho y es la siguiente: además de contenidos, unidades temáticas y enlaces a direcciones web (todo esto debe ser supervisado, considerado y preparado por expertos en temas de psicología y desarrollo humano, es urgente), la pregunta es ¿quiénes van a dialogar, conversar, discutir, debatir con nuestros hijos sobre estos temas de la vida? ¿quién y cómo informará a los escolares las complejidades de la vida humana, en especial las complejidades sexuales y personales?

Un libro puede estar muy bien revisado, con información científica y humanista, dosificado según el grado del escolar y según su nivel de complejidad mental, así como con los dibujos y tareas pertinentes, pero si el que trabaja eso es una maestra o un profesor prejuicioso o ignorante o sexista o fundamentalista $-\mathrm{y}$ disculpen si exageramos- o hasta con alguna psicopatología sexual, en ese caso todos los contenidos, textos y vídeos van a servir de muy poco. Sabemos que el escolar, y si es niño más aún, cree lo que escucha a sus maestros y son estas actitudes, valoraciones e ideologías las que nos preocupan.

Así que aquí va una tarea más para los que manejan la política educativa nacional: evaluar, capacitar, seleccionar y formar a personas idóneas para la tarea pedagógica. Y eso involucra no solo evaluar conocimientos teóricos (está claro que se deben evaluar) sino conocer sus actitudes, sean sexuales, religiosas, éticas, políticas y estéticas.

Estando por iniciar un nuevo año deseamos de corazón que los chicos tengan la oportunidad de convivir y estar acompañados por personas inteligentes, saludables, afectuosas y respetuosas, que disfruten al enseñar y que generen la motivación por aprender y ser mejores en sus estudiantes.

\section{Para que aflore lo mejor de nosotros}

\section{- La Educación Emocional}

"Hoy se habla solamente de la macroeconomía. Me pregunto si algún día volveremos a hablar, aunque sea en voz baja, de la humanidad"

Armando Robles Godoy 
Basta ver parte de la sociedad para darnos cuenta que no venimos funcionando bien. El ex presidente de Uruguay José Mujica decía "no le pidamos a los maestros que arreglen los agujeros que hay en el hogar" (Mujica, 2014, disponible en web); nunca más acertado que hoy. Muchos padres hoy descuidan la educación emocional de sus hijos y esperan que sea la escuela la que se encargue de desarrollarla en ellos. Algunas escuelas intentan hacerlo, pero de pronto muchas lo hacen mal, por falta de apoyo, por falta de tiempo o por no saber cómo hacerlo. La salud mental no es una prioridad en las escuelas, lamentablemente.

Expertos en temas psicoeducativos nos advierten que existen grandes errores en la educación que siguen presentándose a pesar del paso de los años. Veamos: 1. Se ve al alumno en su dimensión intelectual solamente. Sabemos hoy que la razón no sirve sin lo emocional y lo ético /2. El cerebro es sofisticado y plástico y aprende de distintas formas, aunque muchas veces insistimos en enseñar solo de una de ellas / 3 . Los maestros lidian con la diversidad cultural en el aula y las emociones de sus estudiantes todo el tiempo, pero no sabemos qué hacer con ellas / 4. Se practica una absurda jerarquización de las asignaturas, donde se supone (erróneamente) que el álgebra es más importante que el arte o que el curso de lenguaje merece más valor que las manualidades o la filosofía.

¿Cómo poder entonces dar una educación que no solo priorice las notas en los cursos sino lograr promociones de muchachos comprometidos con la vida, que respeten al prójimo y que sean a la vez productivos y tengan éxito? Muchos padres buscan que sus hijos sean competitivos y que "ganen" en todo, sin haberles enseñado a que no solo se miren "el propio ombligo" sino que entiendan que viven en sociedad, con otros como él y dentro de un ecosistema que hay que respetar. Nos hemos demorado en entenderlo, prueba de eso es el nivel de contaminación del planeta. De pronto ser un hombre justo, comprensivo y empático llega a ser visto por estos padres como "debilidad" y "escasez de posibilidades" en esta sociedad arribista, mercantilista y apurada. Nada más lejos de la verdad. Que un joven pueda mantener relaciones cálidas, responsabilizarse de sus decisiones y acciones, ser empático y disfrutar la vida es el máximo logro al que puede aspirar una familia y por qué no una escuela. Pero esto lleva a que los políticos del sector, así como los empresarios dueños de instituciones educativas den un giro copernicano en su visión de lo que la escuela debe ofrecer.

Consideramos que una buena autoestima, desarrollo de la autonomía y de la iniciativa responsable, aprender a conocer y gestionar nuestras emociones, habilidades interpersonales como saber escuchar, saber comunicarse y la cooperación, así como habilidades para la vida (pensamiento positivo, solución de problemas, capacidad de trabajo) son logros importantísimos, quizá por encima de solo saber resolver problemas de exámenes de ingreso universitarios (Arboccó de los Heros, 2015).

Recordábamos al ex presidente del Uruguay José Mujica cuando diferenciaba claramente el papel de la familia y de la escuela. Merece la pena mencionarlo, nos dice: "En la casa se aprende a: saludar, dar las gracias, ser limpio, ser honesto, ser puntual, ser correcto, hablar bien, no decir groserías, respetar a los semejantes y a los no tan semejantes, ser solidario, comer con la boca cerrada, no robar, no mentir, cuidar la propiedad y la propiedad ajena, ser organizado. En la escuela se aprende: matemáticas, lenguaje, ciencias, estudios sociales, inglés, geometría y se refuerzan los valores que los padres y madres han inculcado en sus hijos. Muy dificil es, hacer que el latón brille como el oro." (Mujica, 2014, disponible en web). Luego de esto nos surge la pregunta ¿cómo entonces lograr que "lo dorado" del ser humano aflore, aparezca y nos conmueva? Pues con un mejor trabajo de los padres, la familia y el colegio. Familia y escuela, dos instituciones que andan cojeando desde hace años, dos instituciones en crisis. 
El divulgador científico español Eduard Punset era claro al afirmar que "nuestro sistema de enseñanza imparte competencias trasnochadas". Entonces ¿qué debería gestionar la escuela de hoy, a la luz de tantos problemas sociales, éticos y psicológicos en nuestra sociedad? Pues la escuela (continuando el trabajo inicial de los padres y la familia, ojo con eso) debería enseñar habilidades sociales; buscar el incremento de la autoimagen positiva de los niños; fomentar el aumento de comportamientos prosociales; enseñarle a los chicos como enfrentarse a los conflictos de manera inteligente, ética y eficaz; enseñar a gestionar las emociones y los sentimientos; propiciar el aprendizaje de la autodirección y la capacidad de planificación; es decir, tener metas y trabajar por conseguirlas; propiciar el trabajo en equipo en vez de la competitividad brutal y; a desarrollar una personalidad sana, social, creativa y amorosa. ¿Mucho? ¿Qué pasaría si dejamos de dictar horas y horas de matemáticas y distribuimos mejor esos espacios para que los docentes (bien remunerados, capacitados y con vocación) junto con los especialistas del caso inicien procesos de crecimiento personal y cívico?

No podemos defender una educación solo centrada en las materias, las técnicas y en el currículum, dejando de lado el componente social y emocional, en las relaciones entre los estudiantes, docentes y sociedad. En una palabra, aspirar a una mejora en la salud mental de sus protagonistas: profesores y estudiantes. Curiosamente un estudiante que posea estas capacidades antes señaladas será un estudiante que mostrará un incremento del rendimiento académico. Ya hay investigaciones que demuestran esto. Ya es momento que padres, maestros y políticos empujen hacia el mismo lado, el lado de la educación emocional y la humanización de la escuela. No hay otra.

\section{- El papel de la familia en el educando}

La familia ocupa un lugar central en el rendimiento académico de los hijos. Familias bien constituidas y educadas en valores morales e intelectuales suelen favorecer mejores resultados. Hoy por hoy sabemos que muchas familias son bastante disfuncionales, lo que repercute negativamente en el aparato cognoscitivo, afectivo y axiológico de sus hijos. Además, estamos convencidos de que el nivel educativo de los padres y la familia, el grado de instrucción y una actitud de capacitación constante y apuesta por la cultura, suelen influir muy positivamente en la actitud y la valoración del niño y de la niña hacia el estudio, la lectura y el querer aprender. Así, por ejemplo, se ha encontrado que, en primaria, independientemente de la condición económica de la familia del niño, el nivel educativo de los padres se asocia de manera significativa con su rendimiento (del niño). Esto debe tenerse en cuenta ya que peruanos mal educados se vuelven potenciales limitadores de sus propios hijos.

Uno de los principales determinantes del rendimiento académico es la base educativa que presenta el niño. La educación pre escolar resulta clave en el rendimiento futuro de los estudiantes por lo que el acceso y la calidad del nivel pre escolar es una prioridad. Hemos escuchado de padres de familia que dicen no preocuparse mucho por dónde estudian sus hijos la etapa pre escolar o la primaria y que luego, ya en secundaria o en la universidad esperan poder acceder a una institución seria y prestigiosa. Craso error a la luz de las investigaciones. La base es esencial para cualquier trabajo posterior. Los efectos de una buena base perduran por un período largo de tiempo, incidiendo en la educación secundaria y en la universitaria aún. Recordemos además que cuando hablamos de educación no solo nos referimos al nivel de conocimientos que le vayan a brindar al pequeño. Cuando hablamos de educación hablamos desde una mirada holística: educación cognoscitiva, afectiva y social, axiológica-ética, psicomotriz, artística, e intrapersonal. Le preguntaríamos a esos padres $i$ debemos esperar que se forme una personalidad básica para luego "preocuparnos" por el bienestar personal y el mejor rendimiento de una persona? 


\section{- Rogers y la tendencia actualizante}

Todos nos hemos topado alguna vez con la siguiente circunstancia: ver una plantita creciendo en el lugar menos pensado. En una esquina, en el piso por donde la gente pasa todo el tiempo, en un resquicio de algún lugar, aparece de vez en cuando una planta queriendo crecer y luchando por vivir. Pues bien, hemos recordado esa imagen para hablar del concepto de tendencia actualizante, concepto psicológico que forma parte de la teoría del connotado psicólogo Carl Rogers (1902-1987) uno de los fundadores de la psicología humanística por los años sesenta y creador del enfoque terapéutico centrado en la persona.

La tendencia actualizante sería -según Rogersla natural disposición del ser humano de conservarse, de avanzar, de crecer y de intentar desplegar sus posibilidades. Hay que recordar que cuando él mencionaba esto, la Psicología estaba dominada por teorías que veían al hombre o bien como un ser irracional manejado por deseos e impulsos inconscientes muy difíciles de refrenar (modelo psicoanalítico clásico) o bien como un ser sin mayor albedrío que dependía casi exclusivamente de sus condicionamientos y aprendizajes conseguidos de los modelos y refuerzos del ambiente; es decir, de las contingencias del medio (modelo conductual).

Pero Rogers, que parte de una mirada -a priori- más positiva del ser humano (y donde la consciencia, la intencionalidad y la libertad son intrínsecas a él) estaba convencido que, si se dan ciertas condiciones básicas alrededor del sujeto, este mismo se daría cuenta de lo que necesita y debe realizar para alcanzar aquello que necesita. En unas cuantas palabras, sería autónomo, motivado y tendría confianza en sus posibilidades. La tendencia actualizante o actualizadora sería propia de todo organismo y llevaría a éste a autoconservarse y desarrollarse empleando los medios a su alcance, propone el psicólogo desde su modelo. Está en todo niño, en toda niña, pero cuando las condiciones del entorno no son las favorables y hasta son muy negativas, esa tendencia, esa confianza se bloquea, se estanca; ahí -diríamos- es cuando empieza a aparecer la neurosis.

Las personas deben poder vivir en ambientes seguros, agradables, tranquilos y con posibilidad de apoyo para, a partir de eso, sentir la confianza y las ganas en hacer la propia tarea, la de perseguir nuestros sueños. No es cierto que unas condiciones muy pero muy desfavorables desde pequeños nos hagan mejores (léase por desfavorable: maltratos físicos, humillaciones, falta de oportunidades educativas, pobreza, ausencia de afecto del bueno); la mayoría de las veces nos vuelven psicológicamente vulnerables, desconfiados, hipersensibles, hiperautocríticos. La mirada hacia nosotros y hacia los demás no se ajusta a la realidad; sufrimos de una suerte de ceguera mental. Lastiman nuestro amor propio y esa tendencia natural de avanzar, de lograr lo propuesto, de triunfar, como pensaba el psicólogo estadounidense Carl Rogers. La resiliencia, no lo olvidemos, no es lo solito, no es lo más general; es algo más bien inesperado $\mathrm{y}$ raro $\mathrm{y}$, por eso, estudiado también por la Psicología.

\section{- El corazón del niño, el corazón del hombre}

Uno de los escritores académicos más prolíficos en el terreno de lo psicológico y social fue, sin lugar a dudas, el Dr. Erich Fromm (1900-1980). Obras como: El arte de amar, Psicoanálisis de la sociedad contemporánea y El miedo a la libertad son trabajos clásicos muy leídos y citados. Otro de sus más conocidos libros es El corazón del hombre, título que le da nombre a este artículo. En ese texto, dividido en seis capítulos, Fromm estudia conceptos como la violencia, el narcisismo y la libertad humana. Como psicoanalista, pasa revista a algunas de las ideas de Freud con las que está de acuerdo, así como con aquellas donde está en desacuerdo, cierto que es difícil mantener algunas luego de tantas décadas con cambios no solo en la ciencia y sus posibilidades, sino en el mismo hombre y las sociedades. Fromm no es el primero ni será el último que discuerde con el médico vienés. 
En este texto, El corazón del hombre, Fromm menciona al "síndrome de decadencia" a la situación peligrosa formaba por una triada: amor a la muerte, el narcisismo maligno y la fijación simbiótico-incestuosa. Esta condición mueve al hombre a destruir por el gusto de destruir (posteriormente nos presentará otros tipos de violencia: lúdica, reactiva, por frustración, vengativa), hablamos entonces de una orientación necrófila según Fromm. Lo opuesto a esto es el "síndrome de crecimiento", una orientación biófila; es decir, que consiste en el amor a la vida (opuesto al amor a la muerte); el amor al hombre (opuesto al narcisismo maligno) y la independencia (opuesto a la fijación simbiótico-incestuosa).

¿Cómo llegamos a odiar a la vida? Se pregunta Fromm y bosqueja la siguiente respuesta. "El niño empieza la vida con fe en la bondad, en el amor, en la justicia. El nene tiene fe en el seno materno, en la solicitud de la madre para abrigarlo cuando tiene frío, para aliviarlo cuando está enfermo. Esta fe puede ser en el padre, en la madre, en un abuelo o en alguna otra persona cercana al niño; puede expresarse como fe en Dios. En muchos individuos esta fe se quebranta en edad temprana" (p. 27). Seguidamente afirma: “...Es cierto, desde luego, que todo niño sufre muchas desilusiones; pero lo importante es la agudeza y gravedad de un desengaño particular. Muchas veces esta primera y decisiva experiencia del quebranto de la fe tiene lugar en edad temprana... frecuentemente, el definitivo quebrantamiento de la fe tiene lugar en una edad mucho más avanzada, al ser traicionado por un amigo, por una amante, por un maestro, por un líder religioso o político en quien se confiaba. Rara vez es un solo hecho, sino numerosas experiencias, lo que quebranta acumulativamente la fe de un individuo" (Fromm, 2016, p. 28).

El individuo engañado y desilusionado puede empezar a odiar la vida y cuando esta actitud se instala, el abanico de problemáticas se abre, a saber, desde cuadros depresivos, violencia, adicciones y una vida chata, vacía, sin rumbo.

\section{Conclusión: enseñar para recobrar la esperanza}

"El infierno es un lugar exactamente igual a éste, con la única diferencia que no existe esperanza"

Jorge Luis Borges

En su texto sobre terapia Gestalt (una modalidad de psicoterapia) el belga Georges Pierret nos dice: "Pero tú dirás que la mayor parte de la gente deprimida no ha sufrido un duelo o la pérdida de un amor antes de caer en su depresión. Es exacto. La pérdida que sufre el deprimido es de otro orden: ha perdido la esperanza de la conquista de su felicidad, ha perdido la ilusión en su búsqueda de la alegría. Ya no cree más. Ha perdido la fe." (Pierret, 1990, p. 114). Efectivamente, hoy son muchas personas quienes más que un desorden bioquímico cerebral -el cual va a facilitar un cuadro psicopatológico por supuesto- lo que presentan es una pérdida de la esperanza. Hemos perdido el brillo de los ojos. Ya no tenemos en qué o en quién creer: ni en uno mismo, ni en la familia, ni en los líderes (cuestionados, corruptos, cínicos), ni en los ídolos (hoy cada vez más mediáticos y decepcionantes), ni en el amor, ni en el trabajo y sus posibilidades, ni en el futuro. Como bien dice el autor, hemos perdido ese ánimo (palabra que viene del concepto ánima, alma, soplo de vida, energía), esa alegría que alguna vez tuvimos de chicos. De pronto, muchos problemas, muchas presiones, muchas decepciones nos van aplastando al punto que ese estilo de vida se confunde con la tan conocida depresión nerviosa.

Pocas oportunidades, la falta de afecto desde pequeños, el desamparo paterno y la propia vida que duele y angustia (con sus desavenencias y tragedias) van contribuyendo a la formación de una persona que carece de esa tensión positiva necesaria para vivir, esa energía y rebeldía que ayudan con la tenacidad y la motivación. De ese sentido existencial, como hablamos también en el mundo de la logoterapia. Encima vivimos hoy tiempos donde se asocia casi siempre el bienestar y la felicidad al nivel de consumo, a cuanto compramos, a cuanto tenemos, y eso 
amarga profundamente a miles que no tienen el alcance económico requerido para estar "a la vanguardia". Cierto es que algunos, son conscientes de esto y aprenden a disfrutar no solo gracias a las cosas materiales, sino que giran hacia el plano de la amistad, el afecto y las experiencias enriquecedoras. Aspectos muchos menos efímeros y descartables como los objetos que compramos.

Ramiro Gómez Salas, psicólogo existencial limeño, ha publicado el libro Cuatro modos humanos de existir y -citando, a su vez, al psicoanalista británico Darian Leader quien es autor de La moda negra: duelo, melancolía y depresión- en una parte de su libro escribe lo siguiente: "lo que llamamos depresión es la particular interpretación médica occidental de cierto conjunto de estados biológicos, con la química cerebral como problema de base. Una perspectiva alterna ve la depresión como un resultado de cambios profundos en nuestras sociedades. El surgimiento de las economías de mercado crea una ruptura de los mecanismos de apoyo social y del sentido de comunidad. Las personas pierden la sensación de estar conectadas a grupos sociales y entonces se sienten empobrecidas y solitarias, privadas de recursos, inestables económicamente, sujetas a presiones agudas y con pocos caminos alternativos y esperanzas, caen enfermas. Las causas de la depresión, de acuerdo con este punto de vista, son sociales. Presiones sociales prolongadas acabarán necesariamente por afectar nuestros cuerpos, pero las presiones vienen primero, la respuesta biológica después." (Gómez Salas, 2019, p. 98).

Nos preguntamos cómo salir de esta encrucijada. En lugares donde la gente vive el desempleo, la falta de oportunidades, la violencia, la discriminación, la falta de educación y la ausencia de prácticas éticas, eso sumado (disculpen si sonamos fatalistas) a crianzas a veces dolorosas y familias poco afectivas, es poco probable que haya alegría, respeto, esperanza y sentido de vida. El mercado farmacológico nos brindará ansiolíticos, sedantes, antidepresivos y antipsicóticos cada vez más sofisticados (aunque de acceso restringido por los altos costos de la buena medicina, eso también es una triste realidad), pero quizá eso no surta el tan esperado resultado, pues si atendemos con serenidad esta perspectiva que considera el contexto económico, ético y social como causante (por lo menos co-causante) de la ansiedad y la depresión, más que fármacos lo que necesitaríamos serían otras y mejores circunstancias de vida. Un modus vivendi donde se instale el orden, la justicia, el empleo digno, la educación de calidad, el acceso a oportunidades. Y también la belleza, sí. Hablamos de la dimensión estética tan venida a menos en estos tiempos donde el arte se confunde con el espectáculo televisivo más simplón o vulgar o con el negocio y la producción en serie.

Más que medicina, necesitamos recobrar la fe, en las instituciones, en la política, en la familia y en la escuela. 


\section{REFERENCIAS}

Arboccó de los Heros, M. (23 de mayo de 2017). Diario Oficial El Peruano. La tecnología $y$ el cavernicola. Recuperado de: http:// www.elperuano.pe/noticia-la-tecnologia-ycavernicola-56056.aspx

Arboccó de los Heros, M. (2015). Apuntes psicoeducativos a la luz de las neurociencias. Temática Psicológica 11(1). Lima: Universidad Femenina del Sagrado Corazón. Recuperado de: http://www.unife.edu.pe/ publicaciones/revistas/revista_tematica psicologia_2015/7ARBOCCO.pdf

Chomsky, N. (2012). Manipulación mediática. Recuperado de: http://www.facebook.com/ permalink.php?story_fbid $=223780137725$ $527 \&$ id $=170310603072481$

Dorantes Carrión, J. (Coordinadora) (2018). El cyberbullying y otros tipos de violencia tecnológica en instituciones educativas. Argentina: Brujas.

Editora Perú (1 de marzo de 2017). 4 de cada 10 niños tiene fobia escolar, advierten expertos. Agencia Peruana de Noticia. Recuperado de: https://andina.pe/agencia/noticia-4-cada10-ninos-tiene-fobia-escolar-adviertenexpertos-656082.aspx. Lima-Perú.

Fromm, E. (2016). El Corazón del hombre. México: Fondo de Cultura Económica.

Galeano, E. (10 de junio de 2011). Utopía. Vídeo de youtube. Recuperado de: https:// www.youtube.com/watch?v=1Nxafgc $9 Z 48$
Gómez Salas, R. (2019). Cuatro modos humanos de existir. Lima: APPFE (Asociación Peruana de Psicología Fenomenológico Existencial).

Mujica, J. (7 de agosto de 2014). No le pidamos a los maestros que arreglen los agujeros que hay en el hogar. Recuperado de http:// www.presidencia.gub.uy/comunicacion/ comunicacionnoticias/utucolonia-nicolichmujica-inauguracion.

Peña del Agua, A. M. (2001). Concepto de superdotación. Aspectos psicológicos, personales y sociales. Aula Abierta, $N^{\circ} 77$. España: Universidad de Oviedo.

Pierret, G. (1990). La terapia gestált. España: Mandala Ediciones.

Ponce Alberti, H. (2001). Imágenes críticas de la televisión peruana actual. La función social de los medios de comunicación. Lima: Universidad de San Martín de Porres. Escuela Profesional de Ciencias de la Comunicación.

RAE, Diccionario de la Real Academia Española (2020). Diccionario de la Lengua Española. Décimo tercera edición. Los ciudadanos y las ciudadanas, los niños y las niñas. Versión virtual. Recuperado de: https://www.rae.es/ consultas/los-ciudadanos-y-las-ciudadanaslos-ninos-y-las-ninas

Fecha de presentación: 05-03-20

Fecha de aceptación: 29-05-20 